\title{
Impact of land management practices on tree water use strategy and responses to drought in a dryland plantation
}

\author{
Xiaodong Gao ${ }^{1}$, Hongchen $\mathrm{Li}^{2}$, and Xining Zhao ${ }^{1}$ \\ ${ }^{1}$ Northwest Agriculture and Forestry University \\ ${ }^{2}$ Ludong University
}

May 5, 2020

\begin{abstract}
Extreme droughts of increased frequency due to climate change poses great challenges to the sustainability of plantations in drylands worldwide. Millions of plantations on China's Loess Plateau which are mainly in drylands are threatened by serious degradation due to water scarcity. Here we aim to disentangle the impacts of combinations of terracing and mulching on water use strategy and its response to extreme droughts in a rainfed jujube (Ziziphus jujuba) plantation on the semiarid Loess Plateau, using three-year in situ field observations. Pruned jujube branches and maize straw were mulched on half-moon terraces to form two combined treatments, referred to as JBT and MST, respectively. The efficacy of these two combinations on the water use strategy of jujube trees was compared with terracing alone (SHT) and control (no terrace). We found that extreme drought clearly reduced soil water storage (SWS) under all treatments. However, the combined treatments showed significantly $(\mathrm{P}<0.05)$ higher SWS than the SHT and control. Furthermore, the combined treatments enhanced soil water use in deep layers during both normal and drought years, thus helping jujube trees to resist droughts. Moreover, the extreme drought significantly reduced transpiration whereas the moderate drought increased transpiration at both seasonal and annual scales. Nonetheless, the combined treatments were associated with enhanced transpiration compared to the SHT and control during drought periods. Finally, jujube trees exhibited isohydric behavior which also helped them to cope with prolonged droughts. Overall, the findings here may provide insights into land management of dryland plantations worldwide under climate change.
\end{abstract}

Impact of land management practices on tree water use strategy and responses to drought in a dryland plantation

Running title: Tree water use in relation to land management practices and droughts

Xiaodong $\mathrm{Gao}^{1,2}$, Hongchen $\mathrm{Li}^{3}$, Xining Zhao ${ }^{1,2 *}$

1. Institute of Soil and Water Conservation, Northwest A\&F University, Yangling 712100, Shaanxi Province, China

2. Institute of Soil and Water Conservation, Chinese Academy of Sciences and Ministry of Water Resources, Yangling 712100, Shaanxi Province, China

3. College of Resources and Environment, Ludong university, Yantai 264065, Shandong Province, China.

*Corresponding author: Xining Zhao (zxn@nwafu.edu.cn)

\section{Acknowledgement}

This work was jointly supported by the National Key Research and Development Plan (No. 2016YFC0400204), the National Natural Science Foundation of China (No. 41771316), and the '111'Project (No. B12007). 


\begin{abstract}
Extreme droughts of increased frequency due to climate change poses great challenges to the sustainability of plantations in drylands worldwide. Millions of plantations on China's Loess Plateau which are mainly in drylands are threatened by serious degradation due to water scarcity. Here we aim to disentangle the impacts of combinations of terracing and mulching on water use strategy and its response to extreme droughts in a rainfed jujube (Ziziphus jujuba) plantation on the semiarid Loess Plateau, using three-yearin situ field observations. Pruned jujube branches and maize straw were mulched on half-moon terraces to form two combined treatments, referred to as JBT and MST, respectively. The efficacy of these two combinations on the water use strategy of jujube trees was compared with terracing alone (SHT) and control (no terrace). We found that extreme drought clearly reduced soil water storage (SWS) under all treatments. However, the combined treatments showed significantly $(P<0.05)$ higher SWS than the SHT and control. Furthermore, the combined treatments enhanced soil water use in deep layers during both normal and drought years, thus helping jujube trees to resist droughts. Moreover, the extreme drought significantly reduced transpiration whereas the moderate drought increased transpiration at both seasonal and annual scales. Nonetheless, the combined treatments were associated with enhanced transpiration compared to the SHT and control during drought periods. Finally, jujube trees exhibited isohydric behavior which also helped them to cope with prolonged droughts. Overall, the findings here may provide insights into land management of dryland plantations worldwide under climate change.
\end{abstract}

Key words : water source; soil moisture; transpiration; land development; drought

\title{
1. Introduction
}

Drylands cover more than $40 \%$ of the Earth's land surface and $72 \%$ of them are in undeveloped regions that are home to 2.5 billion people, or $38 \%$ of the world's total population (Huang et al., 2017). Water scarcity impedes the sustainable development of agriculture, economy and society in global drylands (Vohland and Barry, 2009; Schwaerzel et al., 2020). It is projected that climate change is amplifying the intensity and frequency of droughts, causing greater stress on water availability particularly in arid and semiarid areas (Thornton et al., 2014) where it could cause massive tree mortality (Choat et al., 2018). The productivity and sustainability of agroecosystems in drylands during prolonged droughts greatly depend on each crop's capacity to exploit water resources (Grossiord et al., 2017), and on soil management to increase infiltration and minimize evaporation (Zhao et al., 2009).

Understanding the seasonal and annual patterns associated with plants' water use strategies is critical if we are to disentangle how plants acclimate and respond to varying water situations. The seasonal water sources usually vary depending on plant species, wetness, and topography (Allen et al., 2019). Generally, plants can modify their water sources, transpiration rate, or leaf water status under changing conditions in order to cope with drought (Gow et al., 2018). It has been demonstrated that tree species usually shift water use to deep-layer soil water (Gao et al., 2018a; Tang et al., 2018) or groundwater (Barbeta et al., 2016) during prolonged drought, by concentrating more fine roots at greater depths in order to avoid hydraulic failure (Wang et al., 2020). In fact, plants have evolved complex water use strategies in order to adapt to different climates and water regimes, and these include isohydric and anisohydric behavior (McDwell et al., 2008; Luo et al., 2017). Schmidt-Walter et al. (2014) found that the transpiration of a mature poplar (Populus spp. ) plantation was strongly controlled by the stomata, with the plants exhibiting isohydric behavior and a conservative water use strategy in response to drought at two sites with a subhumid climate in Germany. In contrast, Luo et al. (2016) found that two evergreen tree species (Osmanthus fragrans and Cinnamomum camphora ) both exhibited anisohydric behavior in response to an extreme summer drought at a humid site in central southern China. Nevertheless, the information about the water use strategies employed by trees in response to real-world droughts in drylands remains limited. Furthermore, there appears to be few integrated studies considering water source, transpiration and leaf water potential for a given species.

A variety of mulching and terracing measures have been introduced in drylands to reduce water loss through evaporation and runoff. It has been clearly demonstrated that mulching has a great effect on water balance, in terms of increasing soil water content and soil temperature, reducing soil evaporation, and enhancing transpiration and water use efficiency (e.g., Zhang et al., 2007; Singh et al., 2011; Liu et al., 2014). However, 
little is known about how mulching influences seasonal water use within soil profiles. For hilly regions in drylands, various types of terraces have been used to reduce runoff and to promote infiltration (Arnáez et al., 2015; Wei et al., 2016; Chen et al., 2017). However, just terracing without mulching the soil surface could increase soil evaporation during inter-rainfall periods (Li et al., 2018). A combination of terracing and mulching may be a better alternative to either terracing or mulching alone on dryland hillslopes. However, the impact of such a combination on plant water use strategy has not been examined.

The Loess Plateau (LOP), of which almost $100 \%$ can be classified as dryland, is one of the most undeveloped regions in China due to severe soil erosion. Therefore, the Chinese government launched the "Grain for Green" project to reduce both soil erosion and rural poverty. This project encouraged farmers to plant jujube trees (Ziziphus jujubaMill.) on hillslopes to deliver both ecological and economic benefits (Gao et al., 2018b). The planting area and output value of jujube trees exceeded $54.5 \times 10^{4} \mathrm{hm}^{2}$ and 9.4 billion RMB in 2013 (Wang et al., 2016) and supported the livelihood of more than 1 million farmers. However, the sustainability of jujube trees is greatly hindered by water scarcity and the increasing frequency of extreme droughts. Therefore, the main objectives of this study are (1) to investigate the impacts of mulching and terracing combinations on soil moisture and the water use strategy of jujube trees in a semiarid plantation, and (2) to apply the results to address the issues of extreme drought in real world situations.

\section{Materials \& methods}

\subsection{Study site}

The study site was located in the Yuanzegou catchment $\left(37^{\circ} 14^{\prime} \mathrm{N}, 110^{\circ} 20^{\prime} \mathrm{E}\right)$ in the hilly region of the Loess Plateau, China (Figure 1). This site has a semiarid climate: the mean annual precipitation is $481 \mathrm{~mm}$, approximately $70 \%$ of which falls in July, August and September (wet season); the mean annual temperature is 8.6, with the maximum of in July and the minimum of in January (Gao et al., 2014). The catchment is covered by thick loess soils (silt loam) (Gao et al., 2014). The basic soil properties of the study site are presented in Table 1.

/Figure 1/

The area of the whole catchment is approximately $0.6 \mathrm{~km}^{2}$. The uplands comprise three main land use types, i.e., jujube plantations which account for approximately $50 \%$ of the uplands, cropland, and grassland at two different growing stages (Figure 1). The jujube tree is used primarily as a shade tree that also bears fruit. The majority of the jujube trees in this catchment were planted in 2007 at a density of approximately 1650 trees per hectare, in order to improve both green cover and the farmer's income (Gao et al., 2014). The jujube trees on hillslopes were planted in half-moon terraces (also known locally as fish-scale pits), which is one of the primary methods of planting trees on the Loess Plateau (Wei et al., 2016). The size and layout of these terraces is shown in Figure S1. In general, jujube plantations in the hilly region of the Loess Plateau are rainfed because of the high cost of irrigation, which would require runoff water collected in gully bottoms to be pumped upslope. Therefore, the jujube plantations here usually suffer seasonal droughts.

\subsection{Precipitation data}

Historical precipitation data for the period 1960 to 2012 at the study site was derived from the China Meteorological Forcing Dataset (CMFD; He and Yang, 2011). The CMFD was developed by the Institute of Tibetan Plateau Research, Chinese Academy of Science, and include data on air temperature, air pressure, relative humidity, wind speed, downward short-wave radiation, downward long-wave radiation and precipitation at the land surface. The datasets are available via the following link:http://westdc.westgis.ac.cn/data/7a35329cc53f-4267-aa07-e0037d913a21.

The precipitation data during the study period (2014-2016) were recorded by a portable weather station (AR5, Avolon Scientific, USA) located at the study site. The data logger recorded primary meteorological variables including precipitation, wind speed, solar radiation, air temperature and relative humidity every $30 \mathrm{~min}$. 


\subsection{Experimental design}

In order to enhance the ability of jujube trees to resist extreme seasonal droughts, a mulching experiment was conducted at this site in 2013. First, branches pruned from jujube trees during normal management and maize stems were trimmed to lengths of approximately $20 \mathrm{~cm}$ and then used as mulch on the surface of half-moon terraces, applied at a thickness of $15 \mathrm{~cm}$, resulting in two combinations of terracing and mulching (Figure S1), hereafter JBT and MST, respectively. The mulch material can be washed off the terraces by rapid overland flow during heavy rainstorms or blown away by strong winds. Therefore, new branches or maize stems were added to terraces every spring to maintain a constant thickness. Two other treatments, just half-moon terracing (SHT) and the traditional hillslope (control) land management practices, were also examined. Each treatment included four replicates, and each replicate comprised a $24-\mathrm{m}^{2}$ plot $(4 \mathrm{~m} \times 6 \mathrm{~m})$, including three jujube trees. Therefore, there was a total of 16 plots in the experiment.

\subsection{Fine root data}

A portable hand auger $(\Phi=90 \mathrm{~mm})$ was employed to collect fine roots from two different jujube trees outside the 16 plots. Samples were collected down to $500 \mathrm{~cm}$ vertically, at $20 \mathrm{~cm}$ intervals. To reduce sampling uncertainty caused by spatial variability, for each jujube tree, root samples were collected at four locations: two of them along the contour line and the other two downslope from the stem (Figure S2). As shown in the figure, the distance of $\mathrm{A}$ and $\mathrm{C}$ locations was $0.5 \mathrm{~m}$ to the trunk of jujube tree and it was $1.0 \mathrm{~m}$ for the $\mathrm{B}$ and D locations. Mixed root samples were sealed in bags and stored immediately in a refrigerator at 4 ${ }^{\circ} \mathrm{C}$. In the lab, root samples were gently washed in a 2 -mm sieve, and the roots retained on the sieve were removed with tweezers. A Vernier caliper with a precision of $1 \times 10^{-2} \mathrm{~mm}$ was used to separate fine roots ([?]2 $\mathrm{mm}$ ) from coarse roots $(>2 \mathrm{~mm})$. The determination of fine roots and the calculations of fine root length density (FRLD) are given in Li et al. (2017).

\subsection{Soil moisture data}

A TRIME-IPH TDR system (IMKO, Germany) was employed to sample soil moisture in each plot in the 0 depth range. In order to capture detailed temporal patterns of soil water use of jujube trees in the main root soil profiles, soil water content was also recorded using EC-5 sensors (Decagon Inc., USA) every 10 minutes in one plot for each of the four treatments. To install soil moisture sensors, a 320-cm-deep pit was dug and the soil moisture sensors were inserted horizontally at depths of 10,20,40,60,100, 160, 220, and under each of the four plots. Soil water data for the first month after sensor installation were excluded.

The soil moisture outputs $\left(\vartheta_{E}\right)$ obtained via the EC-5 sensors were calibrated at the study site in order to improve accuracy. According to Li et al. (2018), the calibration equation was:

where denotes volumetric soil water content derived by multiplying gravimetric water content by dry soil bulk density.

In this study, daily soil water observations were used to analyze temporal patterns of water use by jujube trees. Daily soil water data clearly has less noise than the 10-minute and hourly data; however, using daily data can obscure the effect of gravity drainage following rainstorms when quantifying soil water use, because the relatively high infiltration capacity of loess soil means that gravity drainage is expected to last less than one day (Zhu et al., 1983). Daily soil moisture data were derived by arithmetically averaging soil moisture data at the 10-min resolution over a whole day.

Here, the 0-100 cm soil layer was defined as "shallow", because this layer clearly exhibits higher temporal variations in soil moisture (Gao et al., 2014) and higher fine root density ( $\mathrm{Li}$ et al., 2017) than the layers below $100 \mathrm{~cm}$. Furthermore, this definition of a shallow layer can also be found in other regions (e.g., Broedel et al., 2017; Yang et al., 2017).

\subsection{Ecophysiological data}


Sap flow rate of stems was used as a proxy for the canopy transpiration rate of jujube trees. For each treatment, three jujube trees were randomly selected from three different plots for sap flow measurements. Therefore, a total of 12 jujube trees were used for this experiment. A FLGS-TDP XM1000 system (Dynamax Co., USA) was used for measuring sap flow rate; this includes 12 thermal dissipation probes (TDPs) with two needles (30 $\mathrm{mm}$ in length and $2 \mathrm{~mm}$ in diameter) and one CR1000 data logger. The installation of the equipment was completed in early March of 2014. On the north side of the trunk and at $20 \mathrm{~cm}$ above the ground on each of the 12 selected trees, one TDP sensor was uniformly and horizontally inserted into the 0-30 mm sapwood layer after peeling off the bark layers; it was then packed using silver membrane. From early March 2014 to the end of 2016, sap flow rate was recorded continuously for all 12 jujube trees. The data from the first two weeks were discarded. Sap flow density $\left(J_{s}\right)$ was calculated based on the equation introduced by Granier (1987). The sap flow rate $(S F)$ was then derived using the following equation, with an assumption of a constant $J_{s}$ across the sapwood profile.

\section{(2)}

where $\mathrm{K}$ denotes a unit conversion coefficient, equal to $0.00864 ; A_{S}$ denotes sapwood area, $\mathrm{cm}^{2}$.

Mid-day leaf water potential $\left(\Psi_{\mathrm{L}}\right)$ was measured on 18 June, 18 July, 18 August, and 18 September in 2015 and on 19 June, 17 July, 19 August, and 19 September in 2016, using a PMS Model 1000 pressure chamber (PMS Instrument, USA).

\subsection{Identification of growing seasons}

At our study site, in normal years, the jujube trees sprout generally in middle April and leaf-fall occurs in mid-October, by which time the fruit are mature. Root growth, however, generally commences earlier and ceases later than shoot growth (Gregory, 2006). Therefore, for this study, we defined the growing season of jujube trees as being from April 10 to October 20. Each growing season was divided into four different growth periods based on records from several years, i.e., the sprouting (SPR) period from April 10 to May 20, the blossom \& young fruit (BYF) period from May 21 to July 10, the fruit swelling (FRS) period from July 11 to September 10, and the fruit maturation (FRM) period from September 11 to October 20.

\subsection{Characterizing the soil water use pattern}

Soil water use by jujube trees in a given layer during the growing season was quantified on the basis of daily changes in soil water storage (SWS) in that layer (Broedel et al., 2017; Christina et al., 2017) because the groundwater is far beyond the plant's rooting depth at our site. The SWS for each layer was computed by multiplying the mean soil water content in this layer () by the layer depth $\left(D_{i}\right)$. In the 0 layer, the soil water content at $10 \mathrm{~cm}$ was used as the mean soil water content. For other depth intervals, the mean soil water content was defined as the arithmetic mean of soil water content at the upper and lower depths. Soil water loss in the 0 layer is generally the result of soil evaporation (He et al., 2013) although this may be small in mulched plots. Nevertheless, in order to ensure consistency between the different plots, the SWS in the 0-10 $\mathrm{cm}$ layer was excluded when quantifying soil water use here. We then computed daily changes () in SWS at eight depth intervals (10-20, 20-40, 40-60, 60-100, 100-160, 160-220, and 220) during the growing season in each year. A negative indicates the use of soil water by jujube trees. The sum of negativein one layer over the growing season was defined as the total water uptake during the growing season from that layer.

Because of the non-uniform depth intervals between the different layers considered, the concept of depth density of water use (DWU) was introduced in order to compare soil water use at different depths. The DWU is defined as the amount of water use per centimeter depth. Furthermore, we calculated the proportion of water use source (PWU) for the shallow (10) and deep (100-280 cm) layers relative to those of the profile as a whole (10) in different years and growing periods to reveal temporal patterns at annual and seasonal scales.

One-way analysis of variance (ANOVA) was used to examine the impacts of combinations of mulching and terracing on SWS, transpiration and mid-day leaf water potential, using the nlme package in R (v.3.5.3, 
$\mathrm{R}$ Core Team 2019). The graphs presented in this paper were drawn using Origin 2016 (OriginLab, Massachusetts, USA).

\section{Results}

\subsection{Precipitation and fine root distribution}

The cumulative frequency of annual total precipitation $\left(\mathrm{P}_{\mathrm{T}}\right)$ and growing-season precipitation $\left(\mathrm{P}_{\mathrm{G}}\right)$ are shown in Figure S3, from 1960 to 2012 at the study site. The medians of $\mathrm{P}_{\mathrm{T}}$ and $\mathrm{P}_{\mathrm{G}}$ were 479.7 and , respectively, which are similar to the annual means of $\mathrm{P}_{\mathrm{T}}()$ and $\mathrm{P}_{\mathrm{G}}()$ during this period. $\mathrm{P}_{\mathrm{T}}$ in 2014()$, 2015()$ and 2016 () corresponded to $55.6 \%, 84.1 \%$ and $59.0 \%$, respectively, in terms of cumulative frequency. $\mathrm{P}_{\mathrm{G}}$ amounted to $56.6 \%, 98.7 \%$ and $67.0 \%$ in 2014 (), 2015 () and 2016 (), respectively. Thus, 2014 was considered to be a normal year, whereas 2015 and 2016 were classified as a severe and moderate drought year, respectively. It is noteworthy that the percentages for $\mathrm{P}_{\mathrm{G}}$ in 2015 and 2016 were clearly lower than for $\mathrm{P}_{\mathrm{T}}$, indicating that less precipitation occurred than in the 2014 growing season.

Figure 2 shows temporal patterns of daily and monthly precipitation for different water years. It was clear that there was a severe spring (April and May) and summer (June and July) drought in 2015. The total precipitation for spring and summer 2015 accounted for only $60.1 \%$ and $21.1 \%$, respectively, of that in 2014 . In July 2015, the total precipitation amounted to only and no water was made available to the jujube trees as a result of almost all of the eight rainfall events (precipitation $<$ ). There was a moderate autumn drought in 2016. The total precipitation in August and September 2016 accounted for only $54.8 \%$ and $39.9 \%$ of that in 2014 and 2015, respectively.

\section{/Figure 2/}

The distribution of fine root length density (FRLD) down the soil profiles from 0 to $500 \mathrm{~cm}$ is shown in Figure 3. In general, the FRLD decreased exponentially with soil depth. The top $300 \mathrm{~cm}$ accounted for $89.9 \%$ of the total fine root length down the entire profile $(0-500 \mathrm{~cm})$, indicating that this is the main fine root layer. The top $100 \mathrm{~cm}$ contained $52.5 \%$ of fine root length. Therefore, we studied soil water storage dynamics and soil water use within the top $300 \mathrm{~cm}$, with the top $100 \mathrm{~cm}$ defined as the shallow layer and below this was the deep layer.

\section{/Figure 3/}

\subsection{Temporal dynamics of soil water storage}

The time series for soil water storage (SWS) during the study period under different treatments are shown in Figure 4. It is clear that both the extreme drought in 2015 (dry spell I) and the moderate drought in the 2016 (dry spell II) greatly decreased the SWS at all soil depths under the different treatments, with a clear lag in the 180-280 cm layer for dry spell I. In particular, the soil water content in the 0-20 cm layer under the SHT and control fell below the permanent wilting point (Table 1). Generally, the treatments that combined terraces and mulches (JBT and MST) exhibited higher SWS values than terraces alone (SHT) or the control. Furthermore, the differences between the combined treatments and the others seemed to be greater during the two dry spells.

\section{/Figure 4/}

The annual average SWS was clearly lower in 2015 and 2016 than in 2014 in the 0-20 cm layer but not in the deeper layers, indicating the effects of seasonal droughts on SWS at the annual scale are probably only apparent in the surface layer. In the $0-20 \mathrm{~cm}$ layer, the combined treatments had, on average, $14.6 \%$ and $30.4 \%$ higher SWS than the SHT and control, respectively, and the difference between these treatments and the control was statistically significant $(P<0.05)$ in 2014 and 2015 . In the $20-100 \mathrm{~cm}$ layer, the combined treatments had, on average, $20.7 \%$ and $36.0 \%$ higher SWS than the SHT and control, respectively, for the different years. The difference was highly significant $(P<0.01)$ for all years, highlighting the advantage of combining terracing and mulching in order to retain soil water. 


\subsection{Spatiotemporal patterns of soil water use}

Soil water use by jujube trees was calculated based on the daily soil water data (Figure S4) acquired using the EC 5 sensors. The depth density of water uptake (DWU) under the four plots in the three different years is shown in Figure 5. The DWU generally decreased exponentially with soil depth, matching the FRLD distribution (Figure 3), and the values approached zero below a depth of $100 \mathrm{~cm}$. The normal year of 2014 generally had higher DWU values than the two drought years in the top, with the exception of the MST plot where values were very similar for the three years. On the other hand, the drought years of 2015 and 2016 had clearly higher DWU values than the normal year 2014.

\section{/Figure 5/}

The proportion of soil water use (PWU) relative to the entire profile (0) is presented in Figure 6, for the shallow layer (0) and three different deep layers (100-160, 160-220 and 220). Overall, the shallow layer was responsible for the majority of water uptake in the profile and the PWU of this layer was generally higher than 63\%, irrespective of plot and year. Significant annual variations in PWU were observed under all plots. In the normal year, the PWU values for the shallow layer ranged from $77.5 \%$ to $87.7 \%$, and decreased by $15.6 \pm 5.3 \%$ and $15.9 \pm 7.9 \%$ (relative ratio; mean \pm one standard deviation) in the drought years of 2015 and 2016, respectively. In contrast, the PWUs in the deep layers dramatically increased in both drought years compared with the normal year. In the serious drought year, the PWUs increased by $78.3 \pm 73.6 \%$, $124.7 \pm 36.9 \%$, and $127.1 \pm 74.8 \%$ (relative ratio; mean \pm one standard deviation) in the $100-160,160-220$, and 220 layers, respectively. In the moderate drought year, even higher relative ratios were observed in the JBT plot.

\section{/Figure 6/}

\subsection{Canopy transpiration and physiological response}

The change in daily transpiration rate $\left(\mathrm{T}_{\mathrm{d}}\right)$ over time during the study period under different treatments is presented in Figure 7. Overall, $T_{d}$ showed clear seasonal patterns independent of year and treatment; $T_{d}$ progressively increased with leaf development in late Spring, peaked from middle Summer to early Autumn (late July to mid-September), and decreased sharply with leaf fall in mid-autumn. The severe drought (dry spell I) clearly reduced $\mathrm{T}_{\mathrm{d}}$ in spring and summer 2015; the transpiration in the BYF period decreased by $22.6 \%$ on average compared to that in 2014. However, the moderate drought in 2016 had negligible negative effects on the time series for $T_{d}$, although the SWS obviously decreased (Figure 4). Nonetheless, this moderate drought seemed to enhance the differences in $\mathrm{T}_{\mathrm{d}}$ between the different treatments; the combined treatments had apparently higher $\mathrm{T}_{\mathrm{d}}$ than the SHT and the control.

\section{/Figure 7/}

The amount of transpiration was calculated for the four growing periods - SPR, BYF, FRS, and FRM (Figure 8). As expected (based on Figure 7), the FRS period had the highest transpiration and accounted from $45.2 \%$, on average, of the whole growing season considering all treatments in different years, while the SPR had the lowest, accounting for only $4.9 \%$, on average. The combined treatments significantly enhanced the transpiration during the four growing periods, with the exception of the SPR in 2015; the FRS period had the highest level $(P<0.001)$ of significant difference whereas the SPR had the lowest level. At the annual scale, the transpiration during the four different growing stages was summed to derive the transpiration for the whole growing season. As shown in Figure 8, 2016 had the highest amount of transpiration, amounting to $206.5 \mathrm{~mm}$ on average, while 2015 had the lowest, with $172.6 \mathrm{~mm}$ on average. Moreover, the combined terracing and mulching also had significantly $(P<0.01$ or 0.001$)$ higher annual transpiration than the other treatments; the MST treatment had the greatest value of $213.5 \mathrm{~mm}$, whilst the control had only $152.3 \mathrm{~mm}$.

\section{/Figure 8/}

The relationship between annual transpiration and the corresponding mean SWS for different treatments and years is shown in Figure 9. Clearly, the annual transpiration significantly $(P<0.01)$ and positively correlated 
with the mean SWS in both the shallow $(0-100 \mathrm{~cm})$ and deep $(100-280 \mathrm{~cm})$ soil layers. This means that the higher transpiration in the combined treatments could be due to the greater soil water availability.

\section{/Figure 9/}

The mid-day leaf water potential $\left(\Psi_{\mathrm{L}}\right)$ during the growing seasons in 2015 and 2016 is presented in Figure 10. Overall, $\Psi_{\mathrm{L}}$ showed relatively moderate temporal variation during the growing seasons, ranging from $-1.04 \pm 0.007$ to $-1.67 \pm 0.068 \mathrm{MPa}$, even in the extreme drought in July 2015 and the moderate autumn drought in 2016. This suggests that the jujube trees exhibited isohydric behavior and a conservative water use strategy in response to extreme droughts. In addition, the combined treatments generally had higher $\Psi_{\mathrm{L}}$ than the SHT and control, especially during the dry spells.

/Figure 10/

\section{Discussion}

\subsection{Tree water use strategy and response to drought}

Soil water is the primary water source for plants in semiarid regions where the ground water is usually deep; this is very much the case on China's Loess Plateau. Because of the paucity of precipitation, plants in drylands usually develop deep root systems to acquire water from deep in the soil or from the groundwater (Gao et al., 2018b). It is predicted that the frequency and intensity of droughts will increase in drylands as a result of climate change (Zhang et al., 2019). The occurrence of extreme droughts increases potential water demand, with intensive soil evaporation and canopy transpiration. Here the extreme spring and summer drought in 2015 reduced soil water storage, particularly in the shallow soil layers (Figure 4). The decrease in shallow water availability increased soil water use from the deep layers during droughts (Figure 5 and 6 ), supporting the findings of Gao et al. (2018b) based on a stable isotopic method. The shift in water use to exploit deep water sources indicates that jujube trees have a flexible water use strategy. This is often ascribed to dimorphic rooting systems, meaning that deep roots become active as shallow roots experience reversible embolism due to severe water stress (Williams and Ehleringer, 2000; West et al., 2012; Gao et al., 2018a). Deep soil water has been considered to be the critical water resource for plants coping with extreme droughts, allowing them to avoid hydraulic failure and mortality, and this applies not just to drylands (Grossoird et al., 2017) but also to subtropical and tropical regions (Choat et al., 2018). However, for drylands where ground water is far beyond the rooting depth, use of deep soil water could result in serious soil desiccation (Jia et al., 2019) which would undermine ecosystem sustainability.

In our study, the peak daily transpiration under the control was gently higher than that recorded for jujube trees without mulching at another study site on the Loess Plateau (Ma et al., 2019). This is because our site has a $6.7 \%$ higher annual mean precipitation as well as higher air temperature compared to the site investigated by Ma et al. (2019). Despite the increase in deep-layer water use during the extreme drought in 2015 (Figure 6), the prolonged drought significantly $(P<0.01)$ reduced the amount of transpiration in the blossom \& young fruit (BYF) period (Figure 8) and the daily transpiration rate (Figure 7). This can be attributed to the decrease in water availability over the whole soil profile during the BYF period. However, Schmidt-Walter et al. (2014) found that water availability did not greatly restrict transpiration rate in a full-grown mature poplar plantation; we think it likely that they did not consider soil water content in layers below $120 \mathrm{~cm}$. In contrast, the moderate autumn drought did not limit the transpiration rate and was actually associated with enhanced transpiration during the fruit swelling (FRS) period (Figure 7 and 8). This could be explained by the high SWS in the $0-280 \mathrm{~cm}$ profile, indicating that there was abundant water provision for transpiration (Figure 8), prior to the occurrence of drought (Figure 4). At the annual scale, there was lower transpiration during the extreme drought year and significantly higher transpiration during the moderate drought year compared to the normal year (Figure 8). This may imply that moderate rather than extreme drought may favor transpiration by trees. However, the jujube trees in this study were not mature and were increasing in size during the study period; the jujube trees in 2016 had a larger canopy basal diameter and tree height than in 2014 and 2015, which would contribute to the higher transpiration in 2016 . 
The jujube trees tended to exhibit isohydric behavior in response to the prolonged droughts, with moderate variation in mid-day leaf water potential during the study period (Figure 10). In contrast to ansiohydric behavior, which could place plants at a great risk of dieback or mortality during extreme droughts (McDwell et al., 2008; Luo et al., 2016), isohydric behavior usually results in a conservative water use strategy and allows plants to avoid hydraulic failure (Schmidt-Walter et al., 2014). In our study, specifically, no dieback was observed in the jujube trees under any treatment after the extreme drought in 2015. Nevertheless, an in-depth investigation is needed to understand the effects of extreme droughts on the hydraulic system of jujube trees, as this is critical to understanding the mechanism of drought impacts (Choat et al., 2018) and to predict how jujube trees will respond to future extreme climates.

\subsection{Effects of combined terracing and mulching on water use strategy}

Terraces, including the half-moon terracing considered here, have been shown to be efficient in interrupting runoff paths, reducing soil and water loss and enhancing infiltration (Wei et al., 2016; Chen et al., 2017). However, terraces alone can enhance soil evaporation and reduce soil water content compared to hillslopes during dry spells (Li et al., 2011). Our results demonstrate that the advantage of half-moon terraces (SHT) compared to a control gradually reduced over the whole soil profile during an extreme drought (Figure 4). In contrast, the efficacy of mulching in reducing soil evaporation has been widely reported, and a variety of mulching materials - films, straw, branches and gravel - have been shown to be effective in enhancing soil water availability (et al., Zhang et al., 2007; Singh et al., 2011; Sun et al., 2012; Liu et al., 2014). In the current study, two common local materials, pruned jujube branches and corn stalks, were mulched on the surface of fish-scale pits to form the combined treatments of terracing and mulching. We found that they significantly increased soil water storage compared to the SHT and the control in both the surface $(0-20 \mathrm{~cm})$ and subsurface $(20-100 \mathrm{~cm})$ layers (Figure 4).

To our knowledge, this study is the first attempt to investigate the effects of agronomic practices on soil water use strategy. We found that the combinations of terracing and mulching clearly modified soil water use patterns, enhancing depth density of water uptake (Figure 5) and the proportion of soil water drawn from the deep layers (Figure 6). This can be attributed to the higher SWS of the subsurface soils in the combined treatments (Figure 4). The increase in soil water availability may promote the growth of fine roots that forage water, due to their hydrotropic nature (Takahashi, 1997), thus enhancing subsurface water use. The combined treatments also significantly increased transpiration rate at daily, seasonal and annual scales (Figures 7 and 8). This can be explained by the strong relationship between SWS and transpiration (Figure 9 ). The greater soil water storage further promoted tree growth and hence more transpiration occurred to meet water demand. Moreover, the higher SWS may also be responsible for the higher mid-day leaf water potential under the combined treatments (Figure 10).

\subsection{Implications}

Since the initiation of the Grain for Green project in 1999, extensive commercial plantations of jujube, apple (Malus domestica), walnut (Juglans regia), and peach (Prunus persica), among others, have been planted on the Loess Plateau, with the aim of delivering ecological and economic benefits (Gao et al., 2014). For example, the area of planted apple trees reached 130 million ha by 2017 (Gao et al., under review). On the Loess Plateau, these commercial plantations are primarily run by smallholder farmers. Because of the complex topography and high cost of irrigation, most of these plantations are rainfed (Gao et al., 2018b). Therefore, efficient use of rainwater and improved SWS are critical to their success. Our results indicate that, compared to traditional hillslopes and terraces alone, the combination of terracing and mulching clearly increases SWS, enhances deep-layer water use and transpiration, and results in higher mid-day leaf water potential, particularly during drought periods. Therefore, the combination of terraces and mulches is strongly recommended for use in commercial plantations on the Loess Plateau, and potentially also in drylands worldwide, thus helping to deliver Sustainable Development Goals (United Nations, 2015).

\section{Conclusions}

We studied how the combination of terracing and mulching influences water use by jujube trees and their 
response to droughts in three different years on the semiarid Loess Plateau of China. We found that both the extreme and moderate droughts clearly reduced soil water storage and modified soil water use patterns, causing a sharp increase in the use of water from deep layers. Furthermore, the extreme rather than moderate drought resulted in a significant decrease in transpiration at both seasonal and annual scales. In addition, the jujube trees exhibited isohydric behavior during the drought periods; this allowed them to cope with extreme drought. Moreover, the combined treatments effectively enhanced soil water availability, deeplayer soil water and canopy transpiration, indicating higher water use efficiency than with traditional land management. These results demonstrate that the combination of terracing and mulching can help jujube trees to survive extreme droughts. These findings provide insights into the effective management of hillslope plantations in drylands, particularly in the context of global warming.

\section{Conflict of interest}

The authors declare that they have no conflict of interest.

\section{References}

Allen, S.T., Kirchner, J.W., Braun, S., Siegwolf, R.T.W., \& Goldsmith, G.R. (2019). Seasonal origins of soil water used by trees. Hydrol. Earth Syst. Sci. , 23, 1199-1210.

Arnáez, J., Lana-Renault, N., Lasanta, T., Ruiz-Flano, P., \& Castroviejo, J. (2015). Effects of farming terraces on hydrological and geomorphological processes. A review. Catena 128, 122-134.

Barbeta, A., Mejía-Chang, M., Ogaya, R., Voltas, J., Dawson, T.E., \& Peñuelas J. (2015). The combined effects of a long-term experimental drought and an extreme drought on the use of plant-water sources in a Mediterranean forest. Glob. Chang. Biol. , 21(3), 1213-1225.

Biswas, A. (2014). Landscape characteristics influence the spatial pattern of soil water storage: Similarity over times and at depths. Catena, 116, 68-77.

Broedel, E., Tomasella, J., Cândido, L.A., \& von Randow, C. (2017). Deep soil water dynamics in an undisturbed primary forest in central Amazonia: Differences between normal years and the 2005 drought. Hydrol. Process., 31, 1749-1759.

Chen, D., Wei, W., \& Chen, L.D. (2017). Effects of terracing practices on water erosion control in China: A meta-analysis. Earth Sci. Rev ., 173, 109-121.

Choat, B., Brodribb, T.J., Brodersen, C.R., Duursma, R.A., Lopez, R., \& Medlyn, B.E. (2018). Triggers of tree mortality under drought.Nature, 558, 531-539.

Christina, M., Nouvellon, Y., Laclau, J., Stape, J.L., Bouillet, J., Lambais, G.R., \& le Maire, G. (2017). Importance of deep water uptake in tropical eucalypt forest. Funct. Ecol ., 31, 509-519.

Gao, X., Wu, P., Zhao, X., Wang, J., \& Shi, Y. (2014). Effects of land use on soil moisture variations in a semi-arid catchment: implications for land and agricultural water management. Land Degrad. Dev. , 25, $163-172$.

Gao, X.D., Zhao, X.N., Li, H.C., Guo, L., Lv, T., \& Wu, P.T. (2018a). Exotic shrub species (Caragana korshinskii) is more resistant to extreme natural drought than native species (Artemisia gmelinii) in a semiarid revegetated ecosystem. Agr. Forest Meteorol ., 263, 207-216.

Gao, X.D., Liu, Z.P., Zhao, X.N., Ling, Q., \& Huo, G.P. (2018b). Extreme natural drought enhances interspecific facilitation in semiarid agroforestry systems. Agric. Ecosyst. Environ ., 265, 444-453.

Granier, A. (1987). Evaluation of transpiration in a Douglas-fir stand by means of sap flow measurements. Tree Physiol ., 3 (4), 309-320.

Gregory, P. (2006). Plant roots: Growth, activity and interaction with soils (Eds.). Blackwell Publishing, . 
Gow, L.J., Barrett, D.J., O'Grady, A.P., Renzullo, L.J., \& Phinn, S.R. (2018). Subsurface water-use strategies and physiological responses of subtropical eucalypt woodland vegetation under changing water-availability conditions. Agr. Forest Meteorol ., 248, 348-360.

Grossiord, C., Sevanto, S., Dawson, T.E., Adams, H.D., Collins, A.D., Dickman, L.T., Newman, B.D., Stockton, E.A., \& McDowell, N.G. (2017). Warming combined with more extreme precipitation regimes modifies the water sources used by trees. New Phytol ., 213, 584-596.

Huang, J., Yu, H., Dai, A., Wei Y., \& Kang, L. (2017). Drylands face potential threat under 2 degC global warming target. Nat. Clim. Chang ., 7, 417-422.

He, J., \& Yang, K. (2011). China Meteorological Forcing Dataset. Cold and Arid at , 2011. doi:10.3972/westdc.002.2014.db.

Jia, Y.H., Li, T.C., Shao, M.A., et al. (2019). Disentangling the formation and evolvement mechanism of plants-induced dried soil layers on China's Loess Plateau. Agr. Forest Meteorol ., 269-270, 57-70.

Li, H.J., Si, B.C., Wu, P.T., \& McDonnell, J. (2019). Water mining from deep critical zone by apple trees growing on loess. Hydrol. Process . 33,320-327.

Li, L., Gao, X., Wu, P., Zhao, X., Li, H., Ling, Q., \& Sun, W. (2017). Soil water content and root patterns in a rain-fed jujube plantation across stand ages on the Loess Plateau of China. Land Degrad. Dev. , 28, 207-216.

Li, P., Zhu, Q.K., Zhao, L.L., Chang, C., \& Zhou, Y. (2011). Soil moisture of fish-scale pit during rainy season in Loess hilly and gully region. T. Chinese Soc. Agr. Eng ., 27 (7), 76-81.

Liu, X.E., Li, X.G., Hai, L., Wang, Y.P., \& Li, F.M. (2014). How efficient is film fully-mulched ridge-furrow cropping to conserve rainfall in soil at a rainfed site? Field Crop Res ., 169, 107-115.

Luo, D.D., Wang, C.K., \& Jin, Y. (2017). Plant water-regulation strategies: Isohydric versus anisohydric behavior. Chin. J. Plant Ecol ., 41, 1020-1032.

Luo, Z.D., Guan, H.D., Zhang, X.P., Zhang, C.C., Liu, N., \& Li, G. (2016). Responses of plant water use to a severe summer drought fortwo subtropical tree species in the central southern China. J. Hydrol. Reg. Stud ., 8, 1-9.

Ma, L.H., Wang, X., Gao, Z.Y., Wang, Y.K., Nie, Z.Y., \& Liu, X.L. (2019). Canopy pruning as a strategy for saving water in a dry land jujube plantation in a loess hilly region of China. Agric. Water. Manag ., $216,436-443$.

McDowell, N., Pockman, W.T., Allen, C.D., Breshears, D.D., Cobb, N., Kolb, T., Plaut, J., Sperry, J., West, A., Williams, D.G., \& Yepez, E.A. (2008). Mechanisms of plant survival and mortality during drought: why do some plants survive while others succumb to drought? New Phytol ., 178 (4), 719-739.

Schmidt-Walter, P., Richter, F., Herbst, M., Schuldt, B., \& Lamersdorf, N.P. (2014). Transpiration and water use strategies of a young and a full-grownshort rotation coppice differing in canopy cover and leaf area. Agr. Forest Meteorol ., 195-196, 165-178.

Schwaerzel, K., Zhang, L.L., Montanarella, L., Wang, Y.H., \& Sun, G. (2020). How afforestation affects the water cycle in drylands: A process-based comparative analysis. Glob. Chang. Biol. , 26(2), 944-959.

Singh, B., Eberbach, P.L., Humphreys, E., \& Kukal, S.S. (2011). The effect of rice straw mulch on evapotranspiration, transpiration and soil evaporation of irrigated wheat in Punjab, India. Agric. Water Manag. , 98, 1847-1855.

Tang, Y.K., Wu, X., Chen, Y.M.,, Wen, J., Xie, Y.L., \& Lu, S.B. (2018). Water use strategies for two dominant tree species in pure andmixed plantations of the semiarid Chinese Loess Plateau. Ecohydrology, 11, e1943. 
Takahashi, H. (1997). Hydrotropism: The current state of our knowledge.J. Plant Res. , 110, 163-169.

Thornton, P.K., Ericksen, P.J., Herrero, M., \& Challinor, A.J. (2014). Climate variability and vulnerability to climate change: a review. Glob. Chang. Biol. , 20, 3313-3328.

United Nations (UN). Transforming our World: the 2030 Agenda for Sustainable Development Annex A/RES/70/1, https://sustainabledevelopment. un.org/post2015/transformingourworld (UN, 2015).

Vohland, K., \& Barry, B. (2009). A review of in situ rainwater harvesting (RWH) practices modifying landscape functions in African drylands. Agric. Ecosyst. Environ ., 131, 119-127.

Wang, J.H. (2016). Effects of climate change on jujube industry and its application on the Loess Plateau. China Meteorological Press, Beijing, China.

Wang, P., Huang, K., \& Hu, S. (2020). Distinct fine root responses to precipitation changes in herbaceous and woody plants: a meta-analysis. New Phytol. , 225, 1491-1499.

Wei, W., Chen, D., Wang, L.X., Daryanto, S., Chen, L.D., Yu, Y., Lu, Y.L., Sun, G., \& Feng, T.J. (2016). Global synthesis of the classifications, distributions, benefits and issues of terracing.Earth Sci. Rev. , 159, 388-403.

West, A.G., Dawson, T.E., February, E.C., Midgley, G.F., Bond, W.J., \& Aston, T.L. (2012). Diverse functional responses to drought in a Mediterranean-type shrubland in South Africa. New Phytol. , 195, 396-407.

Yang, F., Feng, Z., Wang, H., Dai, X., \& Fu, X. (2017). Deep soil water extraction helps to drought avoidance but shallow soil water uptake during dry season controls the inter-annual variation in tree growth in four subtropical plantations. Agr. Forest Meteorol. , 234, 106-114.

Zhang, B.Q., AghaKouchak, A., Yang, Y.T., Wei, J.H., \& Wang, G.Q. (2019). A water-energy balance approach for multi-category drought assessment across globally diverse hydrological basins. Agr. Forest Meteorol. , 264, 247-265.

Zhang, S.L., Lovdahl, L., Grip, H., Jansson, P., \& Tong, Y. (2007). Modelling the effects of mulching and fallow cropping on water balance in the Chinese Loess Plateau. Soil Till. Res ., 93, 283-298.

Zhao, X., Wu, P., Feng, H., Wang, Y., \& Shao, H. (2009). Towards development of eco-agriculture of rainwater harvesting for supplemental irrigation in the semi-arid Loess Plateau of China. J. Agron. Crop Sci ., 195, 399-407.

Zhu, X.M., Li, Y.S., Peng, X.L., \& Zhang, S.G. (1983). Soils of the loess region in China. Geoderma , 29, 237-255.

Table 1. The basic soil properties of the study site.

\begin{tabular}{llllll}
\hline Soil depth & Bulk density & Soil textural fractions (\%) & Soil textural fractions (\%) & Soil textural fractions $(\%)$ & $\mathrm{K}_{\text {sat }}$ \\
\hline$(\mathrm{cm})$ & $\left(\mathrm{g} \mathrm{cm}^{-3}\right)$ & Sand & Silt & Clay & $(\mathrm{mm}$ mir \\
$0-20$ & 1.27 & 19.1 & 64.7 & 16.2 & 1.21 \\
$20-40$ & 1.31 & 18.8 & 64.8 & 16.4 & 1.28 \\
$40-60$ & 1.31 & 17.9 & 63.1 & 19.0 & 1.16 \\
$60-80$ & 1.45 & 17.4 & 64.5 & 18.1 & 0.91 \\
$80-100$ & 1.37 & 18.7 & 62.8 & 18.5 & 0.85 \\
$100-120$ & 1.40 & 16.5 & 62.5 & 21.0 & 0.82 \\
$120-140$ & 1.37 & 16.1 & 63.2 & 20.7 & 0.92 \\
$140-160$ & 1.41 & 16.8 & 62.9 & 20.3 & 0.86 \\
$160-180$ & 1.46 & 16.2 & 64.1 & 19.7 & 0.94 \\
\hline
\end{tabular}


Sand: $0.02-2 \mathrm{~mm}$; Silt: $0.002-0.2 \mathrm{~mm}$; Clay: $<0.002 \mathrm{~mm} . \mathrm{K}_{\mathrm{sat}}$ : saturated hydraulic conductivity; $\vartheta_{\mathrm{s}}$ : saturated water content;

List of figures

Figure 1. The study site: the location of the Yuanzegou catchment on the Loess Plateau (a), land use map (b), and a general view of the jujube plantations (c).

Figure 2. Daily and monthly precipitation distribution at the study site during the study period. The light orange shading indicates dry spells.

Figure 3. Fine root length density of jujube trees at the study site.

Figure 4. Temporal evolution of soil water storage (SWS) under different treatments at different depth intervals during the study period. The columns in the right panels show annual mean SWS for the different treatments. The single, double, and triple asterisks indicate significant differences at $P<0.05, P<0.01$, and $P<0.001$, respectively.

Figure 5. Depth density of water uptake (DWU) by jujube trees under various treatments during different years.

Figure 6 . The proportion of soil water use $(\mathrm{PWU})$ in the studied profile $(0-280 \mathrm{~cm})$ under various treatments during different years.

Figure 7. Time series for daily transpiration $\left(\mathrm{T}_{\mathrm{d}}\right)$ under different treatments during the study period.

Figure 8. Seasonal and annual variation in transpiration under different treatments during the study period. The single, double, and triple asterisks indicate significant differences at $P<0.05, P<0.01$, and $P<0.001$, respectively.

Figure 9. The relationship between annual transpiration and corresponding mean soil water storage (SWS) in the shallow $(0-100 \mathrm{~cm})$ and deep $(100-280 \mathrm{~cm})$ layers.

Figure 10. Mid-day leaf water potential variation for different treatments in 2015 and 2016. The single, double, and triple asterisks indicate significant differences at $P<0.05, P<0.01$, and $P<0.001$, respectively.

\section{Hosted file}

Figure 1.jpg available at https://authorea.com/users/302566/articles/432677-impact-of-landmanagement-practices-on-tree-water-use-strategy-and-responses-to-drought-in-a-drylandplantation

\section{Hosted file}

Figure 2.tif available at https://authorea.com/users/302566/articles/432677-impact-of-landmanagement-practices-on-tree-water-use-strategy-and-responses-to-drought-in-a-drylandplantation

\section{Hosted file}

Figure 3.tif available at https://authorea.com/users/302566/articles/432677-impact-of-landmanagement-practices-on-tree-water-use-strategy-and-responses-to-drought-in-a-drylandplantation

\section{Hosted file}

Figure 4.tif available at https://authorea.com/users/302566/articles/432677-impact-of-landmanagement-practices-on-tree-water-use-strategy-and-responses-to-drought-in-a-drylandplantation

\section{Hosted file}


Figure 5.tif available at https://authorea.com/users/302566/articles/432677-impact-of-landmanagement-practices-on-tree-water-use-strategy-and-responses-to-drought-in-a-drylandplantation

\section{Hosted file}

Figure 6.tif available at https://authorea.com/users/302566/articles/432677-impact-of-landmanagement-practices-on-tree-water-use-strategy-and-responses-to-drought-in-a-drylandplantation

\section{Hosted file}

Figure 7.tif available at https://authorea.com/users/302566/articles/432677-impact-of-landmanagement-practices-on-tree-water-use-strategy-and-responses-to-drought-in-a-drylandplantation

\section{Hosted file}

Figure 8.tif available at https://authorea.com/users/302566/articles/432677-impact-of-landmanagement-practices-on-tree-water-use-strategy-and-responses-to-drought-in-a-drylandplantation

\section{Hosted file}

Figure 9.tif available at https://authorea.com/users/302566/articles/432677-impact-of-landmanagement-practices-on-tree-water-use-strategy-and-responses-to-drought-in-a-drylandplantation

\section{Hosted file}

Figure 10.tif available at https://authorea.com/users/302566/articles/432677-impact-of-landmanagement-practices-on-tree-water-use-strategy-and-responses-to-drought-in-a-drylandplantation 